\title{
Role Of Dermatoglyphics As A Potential Diagnostic Marker For Periodontitis: A Clinical Study
}

\author{
Dr.Snehal Deotale ${ }^{1}$, Dr.Sakshi Dubey ${ }^{2}$, Dr.Deepti Gattani ${ }^{3}$ \\ ${ }^{1}$ (PG student, Department of Periodontology, SDKS Dental College and Hospital, Nagpur, India) \\ ${ }^{2}$ (PG student, Department of Periodontology, SDKS Dental College and Hospital, Nagpur, India) \\ ${ }^{3}$ (Professor, Department of Periodontology, SDKS Dental College and Hospital, Nagpur, India)
}

\begin{abstract}
:
Background: Periodontitis is a chronic inflammatory disease affecting the connective tissue attachment and supporting bone around the teeth. Over the years, the retrospective analysis of the possible etiological factors responsible for periodontal infections has magnified to its brink. The necessity lies in segregating the evidences and acknowledging their potential role in disease pathogenesis. Genetic predisposition might explain such an individual variability that can be predicted by using various cytogenetic markers. However, these studies are far more costly and complicated. The present study was conducted to study the role of palmar dermatoglyphics as a diagnostic tool for periodontal infections.

Materials and methods: The present cross sectional study comprised of 120 subjects who were categorized as those suffering from chronic generalized periodontitis $(n=60)$, in whom variouspalmar patterns were evaluated as compared to healthy controls ( $n=60)$, to find a "dermatoglyphic marker," if any.

Results:A statistically significant higher percentage of ulnar loops (80.5\%) was seen in CGP patients as compared to a majority of whorls $(80.17 \%)$ in the healthy controls $(p<0.001)$. The percentage of presence of palmar accessory tri-radii was similar in both groups $\chi^{2}=0.963(p=0.326)$. Mean a-t-d angle variation was statistically significant in the CGP group as compared to the healthy group $\chi 2=83.796(p=0.000)$.

Conclusion:The results of the study revealed that dermatoglyphics holds promising results for determining the genetic susceptibility of individuals to develop periodontitis.
\end{abstract}

Keywords: Dermatoglyphics, chronic generalized periodontitis, palmar patterns.

\section{Introduction}

The study of definite ridge patterns on the fingers, palms and soles is known as 'Dermatoglyphics'. The concept emerged by the name 'epidermal ridge configurations' and later sculpted into the terminology 'skin casings'. In 1926, Dr. Harold Cummins, father of American fingerprint analysis and Mildo, replaced the existing terms by the word dermatoglyphics. ${ }^{1}$

The initiation of ridge pattern formation occurs in the $6-7^{\text {th }}$ week of the embryonic period and terminates around the $20^{\text {th }}$ week of gestation. In this span of foetal development any abnormal in-utero genetic or non-genetic factors can disturb the patterns. Hence, these are rightly considered as, "the window of intrauterine and congenital abnormalities". ${ }^{2}$

Ridge patterns remain unchanged for life and no two individuals share the same patterns which show a genetic association of dermatoglyphics. The most commonly encountered process of recording the patterns is rapid, non- invasive, economical and thus a convenient technique for the clinician as well as the patients.

In dentistry, assessment of dermatoglyphics has been linked with several disorders like, hereditary gingival fibromatosis, ${ }^{3}$ cleft lip/ palate, ${ }^{4}$ bruxism, ${ }^{5}$ dental caries ${ }^{6}$ etc. Periodontitis is the destruction of the periodontium and has several etiological factors which are accredited with disease onset and progression. Genetics has been associated with periodontitis since ancient times. However, the techniques used to confirm the genetic basis of periodontitis are unavailable at most times and are expensive as well. Various epidemiological studies have been conducted to confirm the role of genetic alterations in the pathogenesis of an antenatal disturbance like periodontitis. ${ }^{7,8}$ In order to alleviate this predicament, research has recently brought dermatoglyphics into the limelight. ${ }^{2}$ The primitive studies by Yilmaz and Atasu ${ }^{8}$ were successful to acknowledge ridge pattern variations in different forms of periodontitis. Genetic correlation of aggressive periodontitis with ridge patterns has also been determined. ${ }^{1}$

The present study was conducted assuming the hypothesis that an antenatal disturbance like periodontitis should manifest in a prenatal event such as dermal ridge formation. Hence the aim of the present study was to assess the role of dermatoglyphics as a diagnostic tool for chronic generalizedperiodontitis (CGP) and to compare these patterns with those of periodontally healthy subjects. 


\section{Materials And Methods}

The study comprised of subjects referred to the Department of Periodontology, Swargiya Dadasaheb Kalmegh Smruti Dental College and Hospital, Nagpur. The study received ethical committee approval of the institution. The participants were explained about the study and an informed consent was obtained.

120 subjects were divided into two groups (Group A\& Group B). Group A comprised of 60 subjects who were diagnosed with CGP after clinical and radiographic examination whereas group B consisted of 60 periodontally healthy subjects. The mean age of the participants were $30 \pm 12$ (Average age: 40). Exclusion criteria was subjects having congenital/ systemic diseases or those diagnosed with aggressive periodontitis.

All the participants were asked to wash their hands with soap in order to remove all the dirt. Then the fingertip and palmar patterns of each participant were recorded by using standard ink method, using blue duplicating ink (Kores India Limited, Mumbai), thick white printing paper (JK Copier, A4 size, $100 \mathrm{~g} / \mathrm{m} 2$ ) and sponge pad. ${ }^{9}$ The finger and palmar prints obtained using this method were studied with the help of magnifying glass. For each individual all ten finger patterns were recorded. The parameters were assessed by both the qualitative and quantitative analysis. The parameters assessed qualitatively were finger print patterns including arches, loops (ulnar loop, radial loop) \& whorls and palmar patterns in which assessment of accessory tri-radii was evaluated as shown in Fig I. Palmar tri radii patterns are of two types: digital (a, b, c, d) and axial/carpal (t). Accessory tri radii which are considered as genetic variants are denoted as a', b', c', d' and t'. ${ }^{10}$

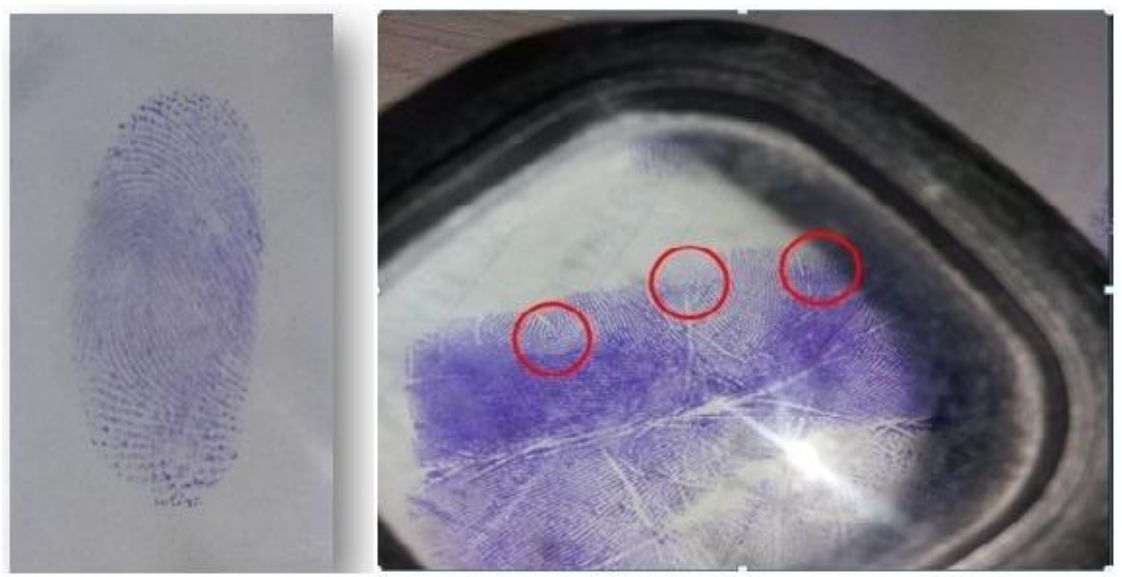

Fig I: Analysis of finger and palmar patterns

The finger and palmar prints were analyzed using Cummins, Mildo and Penrose method. ${ }^{11}$ According to this method the patterns showing maximum frequency in each individual was considered for evaluation. The a-t$\mathrm{d}$ angle which is a palmar pattern is formed between the tri radii a-t-d. ${ }^{12}$ It was measured using a protractor and assessed by quantitative analysis as shown in Fig II.

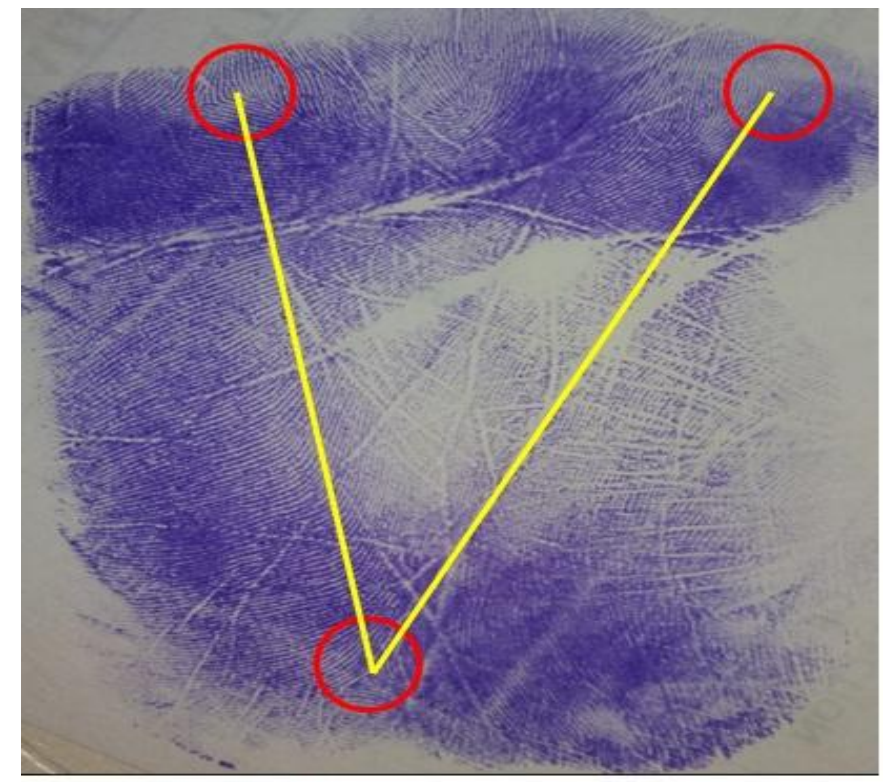

Fig II: Measurement of atd angle 


\section{Statistical Analysis}

Calculation of percentage of fingertip pattern frequency on all 10 fingers of each subject of both groups followed by their comparative evaluation after statistical analysis by paired't' test $(p<0.001)$ was done.Calculation of percentage of palmar accessory tri- radii and ' $a-t-d$ angle' variation, if any, on both palms of each subject of both groups followed by their comparative evaluation after statistical analysis by Chi Square test $(p<0.001)$ was done.All the above analyses were performed using statistical package SPSS software (version 20.0)

\section{IV.1. Qualitative analysis:}

\section{Results}

Table 1 depicts the demographic data of fingerprint patterns in the study groups. The results showed a statistically significant higher percentage of ulnar loops(80.5\%) in CGP patients as compared to a majority of whorls $(80.17 \%)$ in the healthy controls $(\mathrm{p}<0.001)$. The percentage of arches was $10 \%$ in CGP group as compared to $5.67 \%$ in healthy individuals. The percentage of presence of palmar accessory tri-radii was similar in both groups $\chi 2=0.963(\mathrm{p}=0.326)$ as described in Table 2 .

\begin{tabular}{|l|r|r|r|r|}
\hline \multicolumn{5}{|c|}{$\%$ of Pattern Frequency } \\
\hline Group & \multicolumn{1}{|c|}{ Arch } & Ulnar loop & Radial loop & \multicolumn{1}{l|}{ Whorl } \\
\hline $\begin{array}{l}\text { CGP } \\
\text { (in \%) }\end{array}$ & $10 \%$ & $80.5 \%$ & $12.33 \%$ & $5.5 \%$ \\
\hline MEAN & $2.22 \pm 1.07$ & $8.18 \pm 1.30$ & $1.55 \pm 0.88$ & $1.94 \pm 0.96$ \\
\hline $\begin{array}{l}\text { Healthy } \\
\text { (in \%) }\end{array}$ & $5.67 \%$ & $2 \%$ & $10.33 \%$ & $80.17 \%$ \\
\hline MEAN & $2.13 \pm 1.00$ & $1.2 \pm 0.42$ & $2.21 \pm 1.16$ & $8.15 \pm 1.21$ \\
\hline \hline p value & 0.005 & $<0.001$ & $<0.001$ & $<0.001$ \\
\hline
\end{tabular}

Table 1

$P$ value is set at $<0.001$

CGP: Chronic generalized periodontitis

\begin{tabular}{|c|c|c|c|c|c|}
\hline \multicolumn{6}{|c|}{$\%$ of Palmar accessory tri radii } \\
\hline & & & $\mathrm{Grc}$ & up & Total \\
\hline & & & CGP & Healthy & \\
\hline \multirow{4}{*}{$\begin{array}{l}\text { Palmar accessory } \\
\text { tri radii }\end{array}$} & \multirow[b]{2}{*}{ Absent } & Count & 47 & 51 & 98 \\
\hline & & $\begin{array}{l}\text { \% within } \\
\text { Group }\end{array}$ & $79.7 \%$ & $86.4 \%$ & $83.1 \%$ \\
\hline & \multirow[b]{2}{*}{ Present } & Count & 13 & 9 & 22 \\
\hline & & $\begin{array}{l}\text { \% within } \\
\text { Group }\end{array}$ & $20.3 \%$ & $13.6 \%$ & $16.9 \%$ \\
\hline \multirow{2}{*}{\multicolumn{2}{|c|}{ Total }} & Count & 60 & 60 & 120 \\
\hline & & $\begin{array}{l}\text { \% within } \\
\text { Group }\end{array}$ & $100.0 \%$ & $100.0 \%$ & $100.0 \%$ \\
\hline
\end{tabular}

Table 2

$P$ value is set at $<0.001$

\section{CGP: Chronic generalized periodontitis}

\section{IV.2. Quantitative analysis:}

The angle between triradii a, $\mathrm{t}$ and $\mathrm{d}$ (atd angle) was measured on right and left hand separately. Analysis of the percentage of mean a-t-d angle variationwas statistically significant in the CGP group as compared to the healthy group $\chi 2=83.796(\mathrm{p}=0.000)$ as shown in Table 3 . 


\begin{tabular}{|c|c|c|c|c|c|}
\hline \multicolumn{6}{|c|}{$\%$ of a- $\mathbf{t}-\mathrm{d}$ angle variation } \\
\hline & & & Gro & oup & Total \\
\hline & & & CGP & Healthy & \\
\hline \multirow{4}{*}{$\begin{array}{l}\text { atd angle } \\
\text { variation }\end{array}$} & \multirow[b]{2}{*}{ Absent } & Count & 11 & 60 & 71 \\
\hline & & $\begin{array}{l}\text { \% within } \\
\text { Group }\end{array}$ & $16.9 \%$ & $100.0 \%$ & $58.5 \%$ \\
\hline & \multirow[b]{2}{*}{ Present } & Count & 49 & 0 & 49 \\
\hline & & $\begin{array}{l}\% \text { within } \\
\text { Group }\end{array}$ & $83.1 \%$ & $0.0 \%$ & $41.5 \%$ \\
\hline \multirow{2}{*}{\multicolumn{2}{|c|}{ Total }} & Count & 60 & 60 & 120 \\
\hline & & $\begin{array}{l}\% \text { within } \\
\text { Group }\end{array}$ & $100.0 \%$ & $100.0 \%$ & $100.0 \%$ \\
\hline
\end{tabular}

Table 3

$P$ value is set at $<0.001$

\section{CGP: Chronic generalized periodontitis}

\section{Discussion}

The role of dermatoglyphics in periodontal diseases had its inception in a study by Yilmaz et al 1993 in 70 individuals comprising of 36 early onset periodontitis cases, 20 adult periodontitis and 20 periodontally healthy patients and evaluated the quantitative and qualitative patterns of ridged skin. They confirmed the role of heredity in the etiopathogenesis of periodontal diseases. ${ }^{7}$

In a case control study Atasu et al 2005 performed qualitative analysis of fingertip, palms and sole patterns of 158 subjects which encompassed 36 Juvenile Periodontitis (JP), 45 Rapidly Progressing Periodontitis (RPP), 38 Adult Periodontitis (AP) cases compared to 39 healthy controls. A decreased frequency of ulnar loops on all digits and increased frequency of 'e' tri- radii on sole pattern was found in the JP group. An increased frequency of radial loops on second digit \& IV and H loops and ' $t$, b' triradiion the palms in RPP group whereas increased frequency of concentric whorls and ulnar loops on all digits was encountered in AP group. ${ }^{8}$ In the present study an increased frequency of ulnar loop patterns was observed whereas no statistically significant difference was observed in the palmar accessory tri radii frequency.

Gupta and Karjodkar 2013 evaluated the variation in the atd angle amongst other dermatogylphic patterns in precancerous and cancerous lesions of the oral cavity. ${ }^{2}$ This value is between 30 to 65 in healthy individuals where as variation in value $\left(<30^{\circ}\right.$ or $\left.>65^{\circ}\right)$ indicates delayed development of tri- radius ' $\mathrm{t}$ ' and a shift in its position thus altering the angle. ${ }^{12}$ To our knowledge the present study is the first to evaluate this parameter in periodontitis cases. In this study we found that an acute atd angle was formed on the palmar patterns of the test group as compared to the healthy controls. This indicates that there is altered development of the tri radius ' $t$ 'causing a shift in its position.

In another case control study by Devishree et al 2015 evaluating the qualitative parameters on finger tips in 15 aggresive periodontitis as compared to 15 periodontally healthy cases an increased frequency of ulnar loops was found in the test group. ${ }^{1}$ However in our study a similar finding was observed in chronic periodontitis. It can thus be assumed that although an increased frequency of ulnar loopsis a characteristic feature of periodontal diseases, a higher level of genetic analysis is required to categorize the type of periodontitis.

Babitha et al 2016 conducted an observational study to assess correlation between dermatoglyphics, ABO blood group, Rh factor in periodontally healthy $(n=100)$ and diseased patients $(n=100)$. An increased frequency of whorls and loops were encountered in chronic periodontitis patients. Also majority of the test group participants had ' $\mathrm{O}$ ' positive blood group as compared to ' $\mathrm{A}$ ' positive healthy controls. ${ }^{13}$ The results of the present study can be correlated with the aforesaid study.

\section{Conclusion}

Within the limits of the study, it can rightly be concluded that, dermatoglyphics can be a potential diagnostic aid in determining the genetic basis of CGP. The prevalence of a specific pattern predominantly in the latter, justifies that presence of ulnar loops and 'a-t-d angle' variation can be considered as a "dermatoglyphic marker" in the diagnosis of CGP. Further large scale qualitative and quantitative research will aid in proving the rightfulness of the present study. 


\section{References}

[1]. Devishree G, Gujjari SK. Dermatoglyphic Patterns and Aggressive Periodontal Diseases - A Possible Link? IOSR Journal of Dental and Medical Sciences 2015; 14: 69- 72

[2]. Gupta A, Karjodkar F. Role of dermatoglyphics as an indicator of precancerous and cancerous lesions of the oral cavity. ContempClin Den 2013; 4:448- 453

[3]. Skrinjarić I, Bacić M. Hereditary gingival fibromatosis: Report onthree families and dermatoglyphic analysis. J Periodontal Res 1989;24:303-9.

[4]. Mathew L, Hegde AM, Rai K. Dermatoglyphic peculiarities in children with oral clefts. J Indian SocPedodPrev Dent 2005;23:17982.

[5]. Polat MH, Azak A, Evlioglu G, Malkondu OK, Atasu M. The relation of bruxism and dermatoglyphics. J ClinPediatr Dent 2000;24:191-4.

[6]. Atasu M. Dermatoglyphic findings in dental caries: A preliminary report. J ClinPediatr Dent 1998;22:147-9.

[7]. Yilmaz S, Atasu M, Kuru B. A genetic and dermatoglyphic study on periodontitis. J Marmara Univ Dent Fac. 1993;1(4):297-306

[8]. Atasu M, Kuru B et al. Dermatoglyphic findings in periodontal diseases. International Journal of Anthropology 2005;20: 63-75.

[9]. Strong AM. An improved method of palm-printing. Science 1929;69:250-1.

[10]. Gąsiorowski A, Hajn V. A report on the occurrence of accessory triradii in the subdigital area, and carpal triradii on the palm in Polish and Czech populations. Anthropological Review. 2000; 63

[11]. Penrose LS. Fingerprints and palmistry. Lancet 1973;1:1239-42.

[12]. Vashist M, Yadav R, Neelkamal A, A Kumar A. Axial triradius as a preliminary diagnostic tool in patients of mental retardation. The Internet Journal of Biological Anthropology 2009;4(1)

[13]. Dr. Babitha et al. Dermatoglyphics, abo blood groups with Rh factor - An exploring link to Periodontitis International Journal of Current Research 2016; 8:34224-8. 